\title{
Effect of Mechanical Ventilation on Cytokine Response to Intratracheal Lipopolysaccharide
}

Thomas C. Whitehead, M.D., * Haibo Zhang, M.D., Ph.D., † Brendan Mullen, M.D., $\ddagger$ Arthur S. Slutsky, M.D.§

\begin{abstract}
Background: Mechanical ventilation may cause lung injury through the excitation of an inflammatory response and the release of mediators, such as cytokines. The authors tested the hypothesis that intratracheal lipopolysaccharide amplifies the cytokine response to mechanical ventilation.

Methods: Rat lungs were intratracheally instilled with lipopolysaccharide followed by ex vivo mechanical ventilation for $2 \mathrm{~h}$ with low tidal volume of $7 \mathrm{ml} / \mathrm{kg}$ with $3 \mathrm{~cm} \mathrm{H}_{2} \mathrm{O}$ positive end-expiratory pressure (PEEP), high tidal volume of $40 \mathrm{ml} / \mathrm{kg}$ with zero PEEP, medium tidal volume of $15 \mathrm{ml} / \mathrm{kg}$ with $3 \mathrm{~cm}$ $\mathrm{H}_{2} \mathrm{O}$ PEEP, or medium tidal volume and zero PEEP.

Results: In the absence of lipopolysaccharide, lung lavage concentrations of tumor necrosis factor and interleukin $1 \beta$ but not macrophage inflammatory protein 2 were significantly higher in lungs ventilated at high tidal volume/zero PEEP than at low tidal volume. There was a marked increase in lavage tumor necrosis factor and macrophage inflammatory protein 2 concentrations in lungs ventilated at low tidal volume after exposure to intratracheal lipopolysaccharide at doses of $100 \mathrm{ng} / \mathrm{ml}$ or greater. However, in lungs ventilated at high tidal volume, this response to lipopolysaccharide was markedly reduced. In addition, the number of alveolar macrophages recovered in the lavage was significantly lower in lungs ventilated at high tidal volume.
\end{abstract}

Conclusion: Ventilation strategy can modify lung cytokine responses to lipopolysaccharide, likely through an effect on the alveolar macrophage population.

MECHANICAL ventilation is often essential to preserve life in the critically ill, but it may exacerbate lung injury. Animal studies have implicated overdistension of the alveoli and the repetitive opening and closing of small airways as injurious features of mechanical ventilation. ${ }^{1,2}$ Clinical studies have indicated that in patients with acute respiratory distress syndrome, mortality is lower when ven-

This article is accompanied by an Editorial View. Please see: Dreyfuss D, Rouby J-J: Mechanical ventilation-induced lung release of cytokines: A key for the future or Pandora's box? ANESTHESIOLOGY 2004; 101:1-3.

\footnotetext{
* Research Fellow, † Assistant Professor, $₫$ Professor, Departments of Anesthesia and Critical Care Medicine, St. Michael's Hospital, Division of Respiratory Medicine, University of Toronto, ‡ Associate Professor, Department of Pathobiology, Mount Sinai Hospital, University of Toronto, Toronto, Ontario, Canada.

Received from the Departments of Anaesthesia and Critical Care Medicine, St Michael's Hospital, University of Toronto, Toronto, Ontario, Canada. Submitted for publication May 28, 2003. Accepted for publication February 27, 2004 Supported by the Scadding Morriston Davies Fellowship, London, United King dom (Dr. Whitehead), and the Canadian Institutes of Health Research, Ottawa, Ontario, Canada (Drs. Zhang and Slutsky).

Address correspondence to Dr. Slutsky: St Michael's Hospital, 30 Bond Street, Room 4-042, Queen Wing, Toronto, Ontario, Canada M5B 1W8. Address electronic mail to: arthur.slutsky@utoronto.ca. Individual article reprints may be purchased through the Journal Web site, www.anesthesiology.org.
}

tilation is performed using lower tidal volumes $\left(\mathrm{V}_{\mathrm{T}}\right)$. $^{3} \mathrm{How}$ ever, it is not precisely known why such a ventilation strategy leads to an improved outcome, particularly because most deaths from acute respiratory distress syndrome are attributable to multiple organ failure rather than the lung condition per se. ${ }^{4}$

One possibility is that mechanical ventilation initiates or augments an inflammatory response, with release of mediators such as tumor necrosis factor- $\alpha$ (TNF- $\alpha$ ), which influence distal organ function. ${ }^{5}$ In support of this hypothesis was the finding by Tremblay et al. ${ }^{6}$ that ventilation of isolated rat lungs with high $\mathrm{V}_{\mathrm{T}} \mathrm{s}$ and zero end-expiratory pressure (ZEEP) led to far higher lung lavage concentrations of several cytokines, including TNF- $\alpha$, interleukin $1 \beta$ (IL-1 $\beta$ ), and macrophage inflammatory protein 2 (MIP-2), than ventilation at low $\mathrm{V}_{\mathrm{T}}$.

Using similar isolated, nonperfused lungs of rats ventilated for $2 \mathrm{~h}$ with $7 \mathrm{ml} / \mathrm{kg} \mathrm{V}_{\mathrm{T}}$ and $3 \mathrm{~cm} \mathrm{H}_{2} \mathrm{O}$ positive end-expiratory pressure (PEEP) or $42 \mathrm{ml} / \mathrm{kg} \mathrm{V}_{\mathrm{T}}$ and ZEEP, Ricard et $a .^{7}{ }^{7}$ reported that IL-1 $\beta$ and MIP-2 concentrations were higher in lung lavage fluids of lungs ventilated with the high $\mathrm{V}_{\mathrm{T}}$ group, whereas there was no difference for TNF- $\alpha$, as compared with the lungs that were maintained for $2 \mathrm{~h}$ in a statically inflated state at $7 \mathrm{~cm} \mathrm{H}_{2} \mathrm{O}$ airway pressure. In an in vivo model of small rats, Verbrugge et al. ${ }^{8}$ found no pulmonary TNF- $\alpha$ release after mechanical ventilation with a strategy of $32 \mathrm{~cm} \mathrm{H}_{2} \mathrm{O}$ peak inspiratory pressure and $6 \mathrm{~cm} \mathrm{H}_{2} \mathrm{O}$ PEEP. Many factors may have effects on cytokine production. These include differences in the lung size to body weight ratio, ${ }^{9}$ the degree of external stress experienced by the rats before studies, and differences in species and the immunoassays used. Another possibility is that the lungs may have been "primed" by an external cytokine inducer, such as lipopolysaccharide, ${ }^{7}$ which renders the lung more sensitive to the production of large quantities of cytokines when exposed to the additional stress of mechanical ventilation.

In this study, we sought to address the specific issue of whether exposure to lipopolysaccharide, delivered intratracheally, augments the cytokine response of high $\mathrm{V}_{\mathrm{T}}$ ventilation. We used a well-established isolated rat lung model similar to that used in earlier studies for ventilatorinduced lung injury. Unexpectedly, we found that the cytokine response of the lung to lipopolysaccharide is attenuated by ventilation using high $\mathrm{V}_{\mathrm{T}}$ or ZEEP or both. We report here that an alteration in alveolar macrophage activity or location or both, induced by the mechanical ventilation, may underlie this observation. 


\section{Materials and Methods}

\section{Lung Isolation}

The protocol was approved by the animal care committee of the University of Toronto. Pathogen-free male Sprague-Dawley rats weighing 350-400 g (Charles River, St. Constant, Quebec, Canada) were used. Animals were anesthetized with intraperitoneal injection of 30 mg ketamine Ketaset $^{\circledR}$; Wyeth-Ayerst Canada Inc., Guelph, Ontario, Canada) and $6 \mathrm{mg}$ xylazine (Rompun ${ }^{\circledR}$; Bayer, Toronto, Ontario, Canada). A tracheostomy was performed, and the trachea was cannulated with a sterile 14-gauge cannula (Angiocath; Becton Dickson, Sandy, UT). The abdomen was opened, and the animal was exsanguinated by division of the great abdominal vessels. The thoracic cavity was then opened, and the heart and lungs were exposed. The right and left auricles were excised, and the pulmonary circulation was flushed using $30 \mathrm{ml}$ sterile normal saline (Baxter, Toronto, Ontario, Canada) injected into the main pulmonary artery at a rate of $15 \mathrm{ml} / \mathrm{min}$ via a 22-gauge needle. During this period of pulmonary artery flushing, the lungs were ventilated using a volume-cycling rodent ventilator (Harvard model 55-3438; Harvard Apparatus, South Natick, MA) at $7 \mathrm{ml} /$

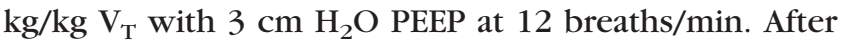
this flushing procedure, the lungs appeared white. The heart and lungs were then excised en bloc.

\section{Mechanical Ventilation}

The lungs were suspended in a humidified box thermostatically maintained at $37^{\circ} \mathrm{C}$, and mechanical ventilation was commenced. To reach similar distribution of lipopolysaccharide in all cases, all lungs were ventilated for $15 \mathrm{~min}$ using $7 \mathrm{ml} / \mathrm{kg} \mathrm{V}_{\mathrm{T}}$ and $3 \mathrm{~cm} \mathrm{H}_{2} \mathrm{O}$ PEEP at a rate of $40 \mathrm{breaths} / \mathrm{min}$. After this period, lungs were allocated, according to the randomization, to one of four ventilation strategies: (1) low $\mathrm{V}_{\mathrm{T}}$ of $7 \mathrm{ml} / \mathrm{kg}$ with $3 \mathrm{~cm}$ $\mathrm{H}_{2} \mathrm{O}$ PEEP $\left(\mathrm{V}_{\mathrm{T}} 7\right)$, (2) high $\mathrm{V}_{\mathrm{T}}$ of $40 \mathrm{ml} / \mathrm{kg}$ with ZEEP $\left(\mathrm{V}_{\mathrm{T}}\right.$ 40), (3) medium $\mathrm{V}_{\mathrm{T}}$ of $15 \mathrm{ml} / \mathrm{kg}$ with $3 \mathrm{~cm} \mathrm{H_{2 }}$ O PEEP $\left(\mathrm{V}_{\mathrm{T}} 15\right.$ PEEP), or (4) medium $\mathrm{V}_{\mathrm{T}}$ and $\mathrm{ZEEP}\left(\mathrm{V}_{\mathrm{T}} 15 \mathrm{ZEEP}\right)$.

\section{Lipopolysaccharide Instillation}

The study was designed so that five doses of lipopolysaccharide $(0,1,10,100,1,000 \mathrm{ng})$ were tested for the $V_{T} 7$ and $V_{T} 40$ ventilation strategies. For each of the intermediate ventilation strategies $\left(V_{T} 15\right.$ PEEP and $V_{T} 15$ ZEEP), only lipopolysaccharide doses of 0 and $100 \mathrm{ng}$ were used. Thus, there were 14 groups, each with five animals. Briefly, the isolated lungs were recruited three times by inflation with $6 \mathrm{ml}$ air and randomly allocated to receive different doses of intratracheal injection of lipopolysaccharide (Escherichia coli serotype 0111:B4; Sigma, Oakville, Ontario, Canada) and different ventilation strategies. The lipopolysaccharide was given in blinded fashion in $0.5 \mathrm{ml}$ sterile normal saline injected intratracheally in a 1-ml syringe, followed by three fur- ther inflations with $6 \mathrm{ml}$ air. Ventilation was then continued for a further $2 \mathrm{~h}$ at a rate of $40 \mathrm{breaths} / \mathrm{min}$ with room air. At the end of this period, lung lavage was performed with $5 \times 10 \mathrm{ml}$ cold normal saline, and the effluent pooled. The lavage fluid was centrifuged at $12,000 \mathrm{~g}$ at $4^{\circ} \mathrm{C}$ for $10 \mathrm{~min}$ (Eppendorf, Hamburg, Germany). Aliquots of the supernatant were frozen at $-70^{\circ} \mathrm{C}$ for subsequent analysis.

\section{Quantification and Differentiation of Cells in Bronchoalveolar Alveolar Lavage}

After centrifugation of the lung lavage, the cell pellet was resuspended in $0.5 \mathrm{ml}$ cold saline. Cell numbers and viability were assessed by exclusion of trypan blue using a hemacytometer at $100 \times$ magnification. Identification of the cells in the lavage was studied by cytospin (Cytospin 2; Shandon, Astmoor, United Kingdom) followed by eosin and methylene blue staining (Harleco, EM Science, Gibbstown, NJ). Cell slides were then analyzed.

\section{Assays of Cytokines}

Lung lavage assays of TNF- $\alpha$, IL1- $\beta$, and MIP-2 were performed using commercially available enzyme-linked immunosorbent assay kits (Biosource International, Inc., Camarillo, CA).

\section{ED-1 Staining for Alveolar Macrophages}

To clarify the location of alveolar macrophages after mechanical ventilation, a second series of experiments was conducted using excised isolated lungs in which the pulmonary circulation had been flushed. The lungs were randomly allocated to receive no ventilation, ventilation at $V_{T} 7$, or $V_{T} 40$ for 30, 60, or $120 \mathrm{~min}(\mathrm{n}=3$ for each condition). Without preceding lavage, lungs were then inflated with $4 \%$ formaldehyde in phosphate-buffered saline. Staining of sections was performed using a specific mouse anti-rat macrophage marker ED-1 (Serotec, Inc., Raleigh, NC) applied at 1:250, followed by biotinylated horse anti-mouse $(1: 200)$ and then Vectastain ${ }^{\circledR}$ Elite ABC kit (Vector Laboratories Inc., Burlingame, CA). Counterstaining was performed with Mayer's hematoxylin. These lung sections were reviewed by a pathologist (B. M.) who was blinded to the study group.

\section{Statistical Analysis}

Results are expressed as mean \pm SEM unless otherwise indicated. Data were analyzed using one-way analysis of variance followed by the Tukey-Kramer test. $P$ values less than 0.05 were considered statistically significant.

\section{Results}

\section{Airway Pressure}

Peak airway pressures are shown in table 1. Peak airway pressures increased progressively, concomitant 
Table 1. Peak Airway Pressures during Ex Vivo Ventilation, cm $\mathrm{H}_{2} \mathrm{O}$

\begin{tabular}{ccccc}
\hline $\begin{array}{c}\text { Ventilatory } \\
\text { Strategy }\end{array}$ & $5 \mathrm{~min}$ & $30 \mathrm{~min}$ & $60 \mathrm{~min}$ & $120 \mathrm{~min}$ \\
\hline $\mathrm{V}_{\mathrm{T}} 7 \mathrm{PEEP}$ & $14.4 \pm 2.1$ & $14.5 \pm 2.8$ & $14.6 \pm 2.8$ & $14.8 \pm 3.0$ \\
$\mathrm{~V}_{\mathrm{T}} 15 \mathrm{PEEP}$ & $26.4 \pm 3.1^{*}$ & $27.1 \pm 3.2^{*}$ & $24.9 \pm 3.3^{*}$ & $23.3 \pm 3.0^{*}$ \\
$\mathrm{~V}_{\mathrm{T}} 15$ ZEEP & $28.2 \pm 2.7 \dagger$ & $28.5 \pm 2.9 \dagger$ & $28.6 \pm 2.5 \dagger$ & $29.2 \pm 2.6 \dagger$ \\
$\mathrm{V}_{\mathrm{T}} 40$ ZEEP & $46.3 \pm 5.7 \dagger$ & $47.1 \pm 6.9 \dagger$ & $44.6 \pm 6.4 \dagger$ & $42.6 \pm 6.1 \dagger$ \\
\hline
\end{tabular}

${ }^{*} P<0.05$ vs. $V_{\mathrm{T}} 7$ PEEP at same time point. $\dagger P<0.05$ vs. any other group at same time point.

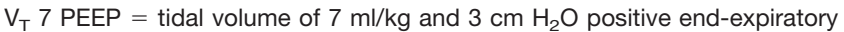
pressure (PEEP); $V_{T} 15$ PEEP = tidal volume of $15 \mathrm{ml} / \mathrm{kg}$ and $3 \mathrm{~cm} \mathrm{H} \mathrm{H}_{2} \mathrm{O} P E E P$; $V_{T} 15$ ZEEP = tidal volume of $15 \mathrm{ml} / \mathrm{kg}$ and zero PEEP; $V_{\mathrm{T}} 40$ ZEEP $=$ tidal volume of $40 \mathrm{ml} / \mathrm{kg}$ and zero PEEP.

with the increase in $\mathrm{V}_{\mathrm{T}}$. In the $\mathrm{V}_{\mathrm{T}} 15$ groups, peak airway pressure was significantly greater in the absence of PEEP $\left(V_{T} 15\right.$ ZEEP) than in its presence $\left(V_{T} 15\right.$ PEEP $)$ at 60 and $120 \mathrm{~min}$. This probably reflects the greater tendency for airways to collapse on expiration in the absence of PEEP, which then require higher pressure to reopen on inspiration. ${ }^{10}$

\section{Lavage Cytokine Concentrations in the Absence of Lipopolysaccharide}

Figure 1 shows lung lavage cytokine concentrations from lungs randomly allocated to the four ventilation strategies that received vehicle normal saline intratracheally but no lipopolysaccharide. Lung TNF- $\alpha$ and IL-1 $\beta$ concentrations were significantly greater in the $V_{T}$ 40 group than in the $\mathrm{V}_{\mathrm{T}} 7$ group (16-fold and 4-fold higher, respectively). These results are consistent with those previously reported from this laboratory. ${ }^{6}$ There was no difference in MIP-2 concentrations among the groups.

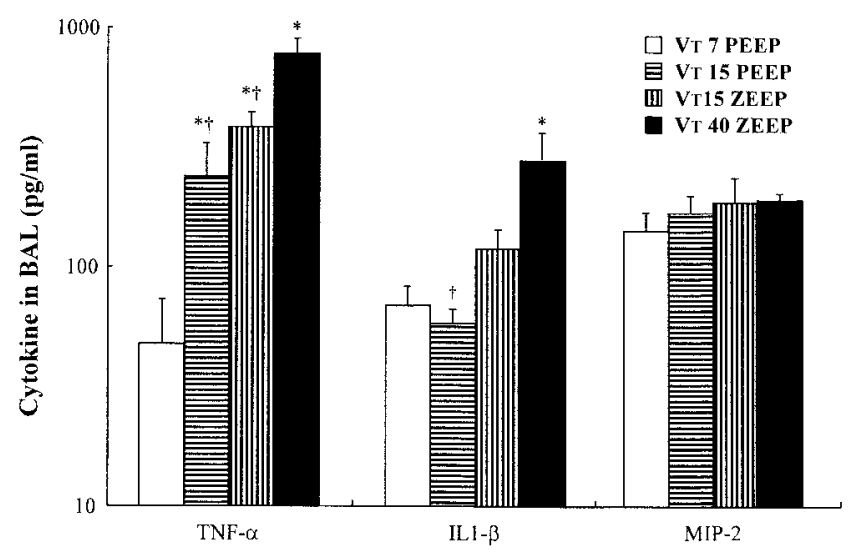

Fig. 1. Lung lavage concentrations of tumor necrosis factor $\alpha$ (TNF- $\alpha$ ), interleukin $1 \beta$ (IL-1 $\beta$ ), and macrophage inflammatory protein 2 (MIP-2) after ventilation with different strategies: tidal volume of $7 \mathrm{ml} / \mathrm{kg}$ and $3 \mathrm{~cm} \mathrm{H} \mathrm{H}_{2} \mathrm{O}$ positive end-expiratory pressure (PEEP) $\left(V_{T} 7\right.$ PEEP), tidal volume of $15 \mathrm{ml} / \mathrm{kg}$ and $3 \mathrm{~cm} \mathrm{H}_{2} \mathrm{O}$ PEEP $\left(V_{T} 15\right.$ PEEP), tidal volume of $15 \mathrm{ml} / \mathrm{kg}$ and zero PEEP $\left(V_{T} 15\right.$ $Z E E P$ ), and tidal volume of $40 \mathrm{ml} / \mathrm{kg}$ and zero PEEP ( $V_{T} 40$ ZEEP). $* P<0.05$ versus $V_{\mathrm{T}} 7$ PEEP; $\dagger P<0.05$ versus $V_{\mathrm{T}} 40$ ZEEP. BAL $=$ bronchoalveolar alveolar lavage.

\section{Lavage Cytokine Concentrations after Intratracheal} Lipopolysaccharide

In lungs ventilated at low $\mathrm{V}_{\mathrm{T}}$ with PEEP, much higher TNF- $\alpha$ and MIP- 2 concentrations are seen after intratracheal instillation of lipopolysaccharide at concentrations of $100 \mathrm{ng}$ or greater (fig. 2). In the $\mathrm{V}_{\mathrm{T}} 7$ group, ventilation after 1,000 ng intratracheal lipopolysaccharide was associated with lavage TNF- $\alpha$ concentrations around 140 times greater than those seen after saline vehicle alone. By contrast, in the $\mathrm{V}_{\mathrm{T}} 40$ group, there was no significant increase in lavage TNF- $\alpha$ concentrations with increasing concentrations of lipopolysaccharide (fig. 2).

Although in the $\mathrm{V}_{\mathrm{T}} 40$ group the concentrations of lavage MIP-2 after 1,000 ng lipopolysaccharide were significantly greater than that after no lipopolysaccharide, the magnitude of this difference was far less than in the $\mathrm{V}_{\mathrm{T}} 7$ groups (approximately 4 -fold increase as opposed to a 26-fold increase). There was no significant effect of increasing concentrations of lipopolysaccharide on lavage IL1- $\beta$ concentrations irrespective of the ventilation strategy (fig. 2).

At intermediate ventilation strategies of $\mathrm{V}_{\mathrm{T}} 15 \mathrm{ml} / \mathrm{kg}$ with and without PEEP $\left(V_{T} 15\right.$ PEEP and $V_{T} 15$ ZEEP), there was tendency to a lower cytokine production in response to an intratracheal lipopolysaccharide dose of $100 \mathrm{ng}$ for TNF- $\alpha$ and MIP-2 but not for IL-1 $\beta$ (fig. 3).

\section{Cells Recovered from the Lavage Fluid}

In all instances, the identity of the lavaged cells (excluding erythrocytes), as assessed in cytospin preparations, was greater than $99.5 \%$ mononuclear cells (data not shown). The proportion of cells that were viable, as judged by exclusion of trypan blue, tended to be higher after low $V_{T}$ than high $V_{T}$ ventilation, but these differences did not reach statistical significance.

At all concentrations of intratracheal lipopolysaccharide, the number of mononuclear cells seen in the lavage fluid was significantly greater in the lungs that had been ventilated at $\mathrm{V}_{\mathrm{T}} 7$ compared with those ventilated at $\mathrm{V}_{\mathrm{T}}$ 40 (fig. 4). Cell counts were also decreased in the intermediate ventilation strategies of $\mathrm{V}_{\mathrm{T}} 15$ with and without PEEP.

Compared with the ventilation strategy, the concentration of intratracheal lipopolysaccharide has a far less marked effect on the number of cells recovered in the lavage fluid (figs. 4).

\section{Immunostaining of Alveolar Macrophages}

Lungs that had not undergone lavage after mechanical ventilation were immunostained with ED-1 for analysis of the distribution of macrophage in the lung sections. In normal lung, the distribution of macrophages was approximately $50 \%$ in intraalveolar space and 50\% in interstitial space including intraparenchymal and septal locations (fig. 5). Lungs that had been ventilated for more than 60 min with $\mathrm{V}_{\mathrm{T}} 40$ had markedly fewer macro- 
Fig. 2. Cytokine production in response to various concentrations of lipopolysaccharide (LPS) in ex vivo lungs ventilated with either high tidal volume $(40 \mathrm{ml} / \mathrm{kg}$ [ $\left.\left.V_{T} 40\right]\right)$ or low tidal volume $(7 \mathrm{ml} / \mathrm{kg}$ and $3 \mathrm{~cm} \mathrm{H}_{2} \mathrm{O}$ positive end-expiratory pressure $\left.\left[V_{T} 7\right]\right) .{ }^{*} P<0.05$ versus $L P S=0$ for $V_{T} 7 ; \dagger P<0.05$ between groups at the identical concentration of LPS, respectively. BAL = bronchoalveolar alveolar lavage; IL-1 $\beta=$ interleukin $1 \beta$; MIP-2 = macrophage inflammatory protein 2; TNF- $\alpha=$ tumor necrosis factor $\alpha$.
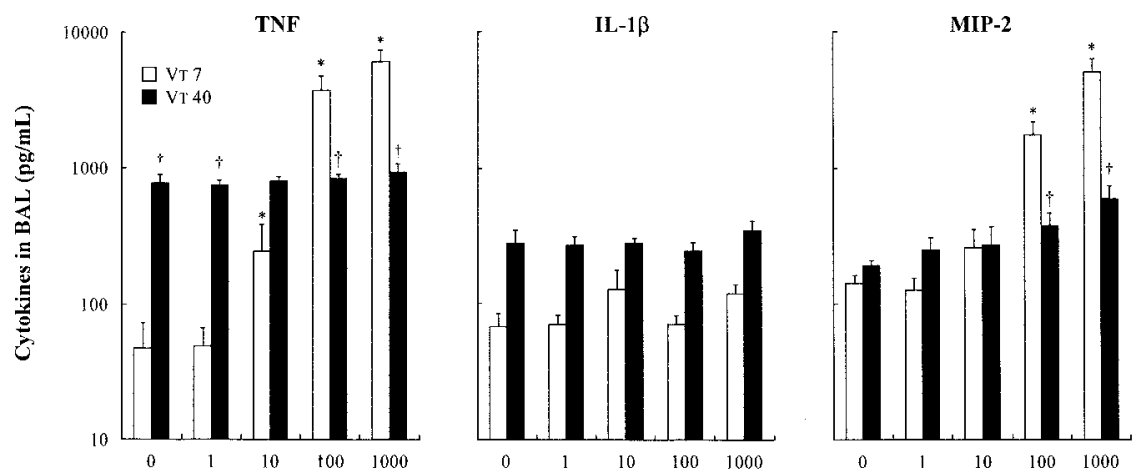

Concentration of intratracheal LPS (ng) phages in the alveolar space but much more in interstitial space than those ventilated with $\mathrm{V}_{\mathrm{T}} 7$, a less injurious strategy (fig. 5).

Figure 6 shows the representative lung slides after ventilation using two different strategies for $120 \mathrm{~min}$ and stained with the anti-rat macrophage ED-1 antibody. In the lung ventilated with $\mathrm{V}_{\mathrm{T}} 7$, intraalveolar macrophages are evident, whereas no macrophages are seen within the alveolar space in lung sections after ventilation at $V_{T} 40$.

\section{Discussion}

The main findings of the study are that the ventilation strategy used has great effects on lung cytokine response to lipopolysaccharide, which was associated with changes in the distribution of macrophages in the lung.

The model we used of an ex vivo nonperfused lung has advantages and disadvantages as a model system. The main advantages are that it allows one to directly assess the impact of mechanical factors (i.e., due to mechanical ventilation) on mediator release without the complications inherent in an in vivo model in which large $\mathrm{V}_{\mathrm{T}} \mathrm{S}$ impact hemodynamics, which could alter mediator release, lead to activation of circulating inflammatory cells, or both. In addition, because there is no chest wall, at end-expiration with zero PEEP, there is complete collapse of the lung, magnifying atelectrauma ${ }^{11}$ (damage due to collapse and repetitive reopening of collapsed lung regions). These factors likely account for the lack of a cytokine response noted in in vivo studies of animals with normal lungs. ${ }^{8,12}$ A number of the advantages described above are disadvantageous in terms of direct application of the findings to the clinical setting. In vivo, the interaction between the lung and the pulmonary circulation is likely to be important in the response to mechanical ventilation. ${ }^{13}$ In addition, the degree of stress imposed by overdistension and atelectrauma in this model is much greater than that observed in vivo. Finally, the lungs are ischemic for more than $2 \mathrm{~h}$, and this may add to the injury being studied. Nonetheless, based on human studies, it seems that many of the findings observed in this model have been observed in the clinical setting. $3,14,15$

In the absence of lipopolysaccharide, ventilation with a $V_{T}$ of $40 \mathrm{ml} / \mathrm{kg}$ and ZEEP led to significantly higher concentrations of TNF- $\alpha$ and IL- $1 \beta$ in lung lavage than ventilation with a $\mathrm{V}_{\mathrm{T}}$ of $7 \mathrm{ml} / \mathrm{kg}$. In this respect, our results are qualitatively similar to those obtained in this laboratory by Tremblay et al. ${ }^{6}$ but differ from those of Ricard et $a l^{7}$ Unlike both groups, we did not find a significant difference in lavage MIP-2 concentrations between the different ventilation strategies in the absence of lipopolysaccharide, although there was a trend toward greater concentrations with the more injurious ventilation. A possible explanation for the discrepancy in MIP-2 observations may lie in the experimental condi-
Fig. 3. Effect of different ventilation strategies on lung lavage concentrations of tumor necrosis factor $\alpha$ (TNF- $\alpha$ ), interleukin $1 \beta$ (IL-1 $\beta$ ), and macrophage inflammatory protein 2 (MIP-2) in the presence or absence of $100 \mathrm{ng}$ intratracheal lipopolysaccharide (LPS). ${ }^{*} P<0.05$ versus $V_{T} 7$ control; $\uparrow P<0.05$ versus $V_{T} 7$ with LPS; $\mathbb{} P<0.05$ between groups at the identical conditions, respectively. $\mathrm{BAL}=$ bronchoalveolar alveolar lavage; PEEP = positive end-expiratory pressure.
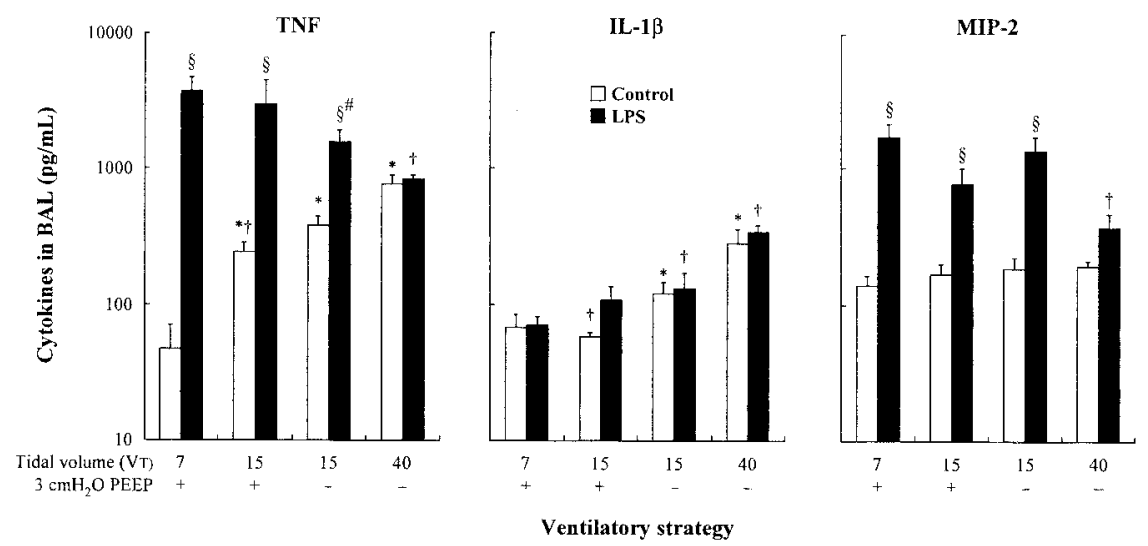


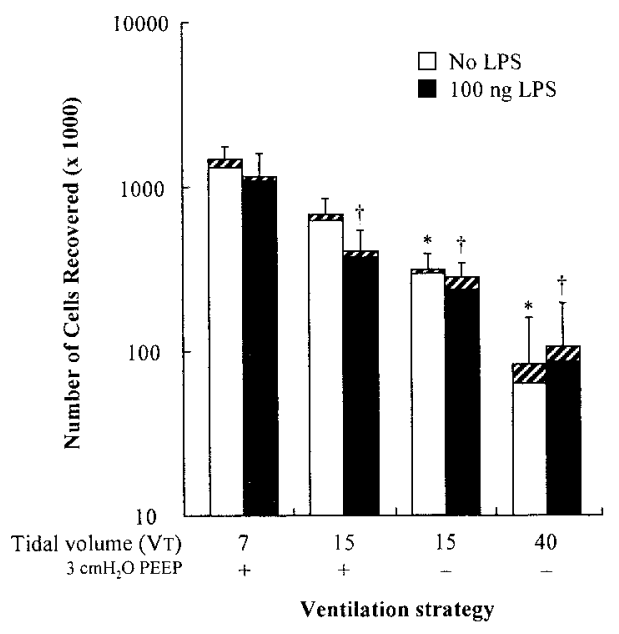

tions distinct in this study from the previous. In the current study, we ventilated lungs in which the pulmonary circulation had been flushed, thereby removing or reducing the influence of immune cells such as neutrophils that may themselves produce MIP-2 or influence its production by other cells. ${ }^{16}$

Tremblay et $a{ }^{6}{ }^{6}$ found that large $\mathrm{V}_{\mathrm{T}}$ ventilation led to release of high concentrations of various inflammatory cytokines, including TNF- $\alpha$, IL- $1 \beta$, and MIP-2 in isolated rat lung. In the current study, we tested the hypothesis that exposure of the lungs to lipopolysaccharide before ventilation might augment the release of inflammatory cytokines in response to mechanical ventilation. In vitro studies suggested that this might be the case. Pugin et $a l .^{17}$ exposed primary human alveolar macrophages to cyclic mechanical stretch in the presence and absence of lipopolysaccharide. Stretch alone (without lipopolysaccharide) led to significantly greater production of interleukin 8, the human homolog of rodent MIP-2, compared

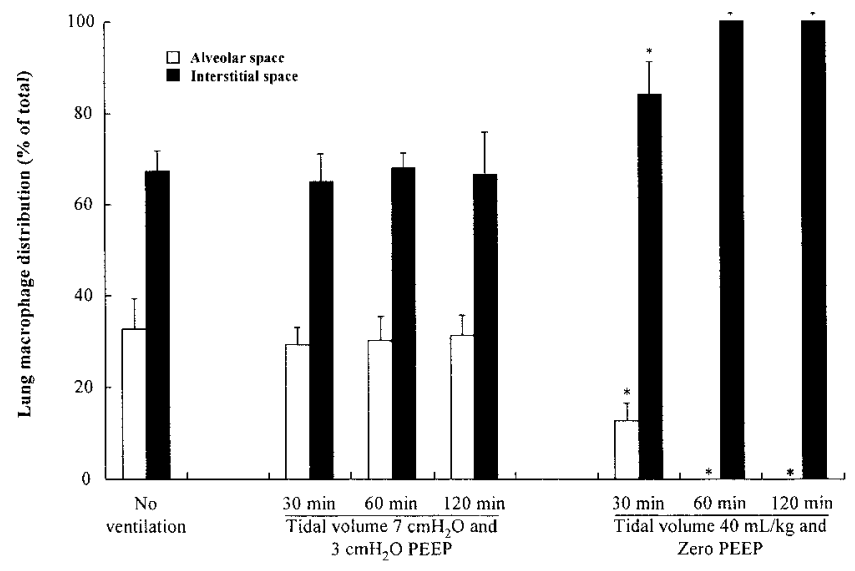

Fig. 5. Alveolar macrophage distribution during mechanical ventilation. Alveolar macrophages were stained with mouse anti-rat macrophage ED-1 antibody. Markedly fewer macrophages were seen in alveolar space after ventilation with tidal volume of $40 \mathrm{ml} / \mathrm{kg}$ and zero positive end-expiratory pressure (PEEP) compared with those ventilated with tidal volume of 7 $\mathrm{ml} / \mathrm{kg}$ and $3 \mathrm{~cm} \mathrm{H}_{2} \mathrm{O}$ PEEP at 60 and $120 \mathrm{~min}$. ${ }^{*} P<0.05$ versus no ventilation at the identical compartment, respectively. with static controls, but no increase in TNF- $\alpha$ or IL-6. Exposure of the resting macrophages to lipopolysaccharide led to significant release of all three cytokines, but their release was considerably greater in the presence of cyclic stretch. Similarly, Mourgeon et al. ${ }^{18}$ showed that mechanical stretch of fetal rat lung cells increased MIP-2 secretion in response to lipopolysaccharide.

In our study, lipopolysaccharide was delivered at low dose ( $\leq 1 \mu \mathrm{g}$ ) into the lungs by the intratracheal route immediately before ventilation. In the earlier studies using isolated lungs, the effect of lipopolysaccharide on cytokine production was studied by administering intravenous lipopolysaccharide approximately $1 \mathrm{~h}$ before removal of the lungs. ${ }^{6,7}$ Because the cytokine response of lipopolysaccharide is largely confined to the compartment into which the lipopolysaccharide is delivered, ${ }^{19}$ we reasoned that intratracheal lipopolysaccharide would exert a much greater influence on the cytokine response to ventilation. Our results showed an effect opposite to what we had hypothesized and indicate that high $\mathrm{V}_{\mathrm{T}}$ ventilation can markedly reduce the release of inflammatory cytokines in response to intratracheal lipopolysaccharide. This was most striking with respect to TNF- $\alpha$ production. These results suggest that the cell response to lipopolysaccharide stimulation may vary depending on ventilatory strategies. Given that the pulmonary vasculature had been flushed to minimize neutrophil involvement in cytokine production after mechanical ventilation, we focused on the role of alveolar macrophages because they are an important cell type to produce lung cytokines and can transmigrate and relocate across intraalveolar spaces.

In a previous study using immunohistochemistry staining technique, we demonstrated that pulmonary epithelium is an important source of cytokine production in response to mechanical ventilation. ${ }^{20}$ In that study, we did not examine the contribution of epithelium to the quantitative cytokine response. In the current study, we extend this observation by suggesting that pulmonary macrophages may also play a role in the cytokine re- 

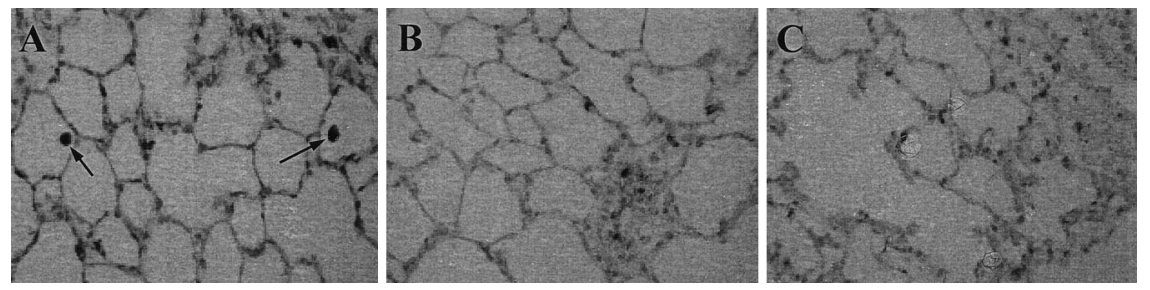

Fig. 6. Sections of lungs ventilated ex vivo using different strategies for 120 min and stained with the mouse anti-rat macrophage ED-1 antibody. In the lung ventilated with tidal volume of $7 \mathrm{ml} / \mathrm{kg}$ and $3 \mathrm{~cm} \mathrm{H}_{2} \mathrm{O}$ positive end-expiratory pressure, intraalveolar macrophages are evident $(A)$, whereas fewer macrophages are seen within the alveolar space after ventilation at tidal volume of $15 \mathrm{~cm} \mathrm{H}_{2} \mathrm{O}$ and zero end-expiratory pressure $(B)$ and $40 \mathrm{~cm} \mathrm{H}_{2} \mathrm{O}$ and zero end-expiratory pressure $(C)$.

sponse using this model. It is not clear from the current study whether the response is solely dependent on any one cell type or whether there is cross-talk between pulmonary macrophages and the pulmonary epithelium in eliciting release of cytokines. In addition, it is unknown whether this mechanism is also involved in the ventilator-induced decompartmentalization of TNF- $\alpha$ in the absence of PEEP as previously reported by other investigators. $^{21-24}$

We focused the effect of different ventilatory strategies on alveolar macrophage population and found that far fewer macrophages were recovered in the lung lavage after high $\mathrm{V}_{\mathrm{T}}$ than low $\mathrm{V}_{\mathrm{T}}$ ventilation. Therefore, our results suggest that ventilation with high $\mathrm{V}_{\mathrm{T}}$ exerts an effect on the alveolar macrophage such that they are less easy to recover in lung lavage and have a reduced capacity to respond to lipopolysaccharide exposure. Immunohistochemistry staining using the specific marker ED-1 confirmed the reduction in the number of alveolar macrophages after high $\mathrm{V}_{\mathrm{T}}$ mechanical ventilation. It was not possible to judge whether the integration of alveolar macrophages was altered by our assays; however, it seemed that the alveolar macrophages were relocalized from alveolar space to interstitial space including intraparenchymal and septal sites.

These observations are consistent with those reported by Imanaka et al., ${ }^{25}$ who studied the effect of different ventilation strategies on alveolar macrophages using an in vivo rat model. They found that fewer macrophages $\left(150 \times 10^{3} v\right.$ s. $\left.1,000 \times 10^{3}\right)$ were recovered in those animals who were ventilated for $40 \mathrm{~min}$ with a peak airway pressure of $45 \mathrm{~cm} \mathrm{H}_{2} \mathrm{O}$ than those ventilated with $7 \mathrm{~cm} \mathrm{H}_{2} \mathrm{O}$. However, the authors did not discuss why fewer alveolar macrophages were recovered after high peak airway pressure ventilation.

Broadly speaking, there are several possible explanations for the reduced recovery of alveolar macrophages seen in our study. An increased adherence of the alveolar macrophages to alveolar epithelium may make them less easily recovered by lavage. In support of this hypothesis was the finding of increased expression of the adhesion molecules CD11b and CD54 in the relatively few alveolar macrophages recovered after high peak airway pressure ventilation in the work of Imanaka et al. ${ }^{25}$ However, we did not observe the presence of alveolar macrophages within the alveoli of lungs that were ventilated with high $\mathrm{V}_{\mathrm{T}}$.

Death of the alveolar macrophages induced by high $\mathrm{V}_{\mathrm{T}}$ may have resulted in the low population. This might take the form of apoptosis or necrosis. However, apoptosis of alveolar macrophages would not in itself necessarily lead to their absence in the lung lavage. Also, in this ex vivo model, we have not found greater evidence of apoptosis by terminal deoxynucleotidyl transferase biotin-dUTP nick end labeling staining after high $\mathrm{V}_{\mathrm{T}}$ compared with low $V_{T}$ ventilation. Furthermore, the proportion of viable alveolar macrophages was not different between the low and high $\mathrm{V}_{\mathrm{T}}$ groups. Necrosis of the alveolar macrophages, with total loss of cellular architecture, may be a potential explanation for the reduced numbers seen after high $\mathrm{V}_{\mathrm{T}}$ ventilation seen in our study and that of others. ${ }^{25}$ However, it would be surprising if ventilation was responsible for such a dramatic degree of damage to the alveolar macrophages within a short period of $2 \mathrm{~h}$.

Relocation of alveolar macrophages outside the alveolar compartment is the most likely explanation. We were able to show that the number of interstitial macrophages was greater than that in alveolar compartment after high $\mathrm{V}_{\mathrm{T}}$. It is probable that the decreased TNF- $\alpha$ secretion in response to intratracheal lipopolysaccharide seen with high $V_{T}$ ventilation was due to a reduction of alveolar macrophage population.

In recent years, considerable evidence has accumulated suggesting that mechanical ventilation, particularly of injured lungs, causes the release of inflammatory mediators, which may then pass into the circulation. ${ }^{6,14,26}$ This provides a possible explanation of how mechanical ventilation causes or exacerbates distal organ dysfunction. ${ }^{5}$ Alveolar macrophages are central in the early response of the lung to air-space pathogens. A reduction in this population with high $\mathrm{V}_{\mathrm{T}}$ ventilation, suggested by our results and others, ${ }^{25}$ may increase susceptibility to infection. In addition, the macrophage may have other important roles in acute respiratory distress syndrome, regulating the inflammatory process by clearing apoptotic neutrophils. ${ }^{27}$ In a study of patients with acute respiratory distress syndrome, Steinberg et al. ${ }^{28}$ found that increased numbers of alveolar macrophages correlated with survival, suggesting that these cells have a benefi- 
cial role in the condition, although this may simply be a reflection of less severe underlying lung injury. We believe that further studies are needed to substantiate our findings, which suggest that the macrophage population and the early innate immune response of the lung can be profoundly affected by mechanical ventilation.

\section{References}

1. Webb HH, Tierney DF: Experimental pulmonary edema due to intermittent positive pressure ventilation with high inflation pressures: Protection by positive pressures end-expiratory pressure. Am Rev Respir Dis 1974; 110:556-65

2. Dreyfuss D, Soler P, Basset G, Saumon G: High inflation pressure pulmonary edema: Respective effects of high airway pressure, high tidal volume, and positive end-expiratory pressure. Am Rev Respir Dis 1988; 137:1159-64

3. The Acute Respiratory Distress Syndrome Network: Ventilation with lower tidal volumes as compared with traditional tidal volumes for acute lung injury and the acute respiratory distress syndrome. N Engl J Med 2000; 342:1301-8

4. Ferring M, Vincent JL: Is outcome from ARDS related to the severity of respiratory failure? Eur Respir J 1997; 10:1297-300

5. Slutsky AS, Tremblay LN: Multiple system organ failure: Is mechanical ventilation a contributing factor? Am J Respir Crit Care Med 1998; 157:1721-5

6. Tremblay L, Valenza F, Ribeiro SP, Li J, Slutsky AS: Injurious ventilatory strategies increase cytokines and c-fos m-RNA expression in an isolated rat lung model. J Clin Invest 1997; 99:944-52

7. Ricard JD, Dreyfuss D, Saumon G: Production of inflammatory cytokines in ventilator-induced lung injury: A reappraisal. Am J Respir Crit Care Med 2001; $163: 1176-80$

8. Verbrugge SJ, Uhlig S, Neggers SJ, Martin C, Held HD, Haitsma JJ, Lachmann B: Different ventilation strategies affect lung function but do not increase tumor necrosis factor-alpha and prostacyclin production in lavaged rat lungs in vivo. ANESTHESIOLOGY 1999; 91:1834-43

9. Malus E, Kim CH, Zhang H, Slutsky AS: Setting tidal volume based on body weight may not be optimal in studies of ventilator induced lung injury (abstract). Am J Respir Crit Care Med 2002; 165:A787

10. Macklem PT, Proctor DF, Hogg JC: The stability of peripheral airways. Respir Physiol 1970; 8:191-203

11. Slutsky AS: Lung injury caused by mechanical ventilation. Chest 1999 116:9S-15S

12. Wrigge H, Zinserling J, Stuber F, von Spiegel T, Hering R, Wetegrove S, Hoeft A, Putensen C: Effects of mechanical ventilation on release of cytokines into systemic circulation in patients with normal pulmonary function. ANESTHESOLOGY 2000; 93:1413-7

13. Marini JJ, Hotchkiss JR, Broccard AF: Bench-to-bedside review: Microvas- cular and airspace linkage in ventilator-induced lung injury. Crit Care 2003; $7: 435-44$

14. Ranieri VM, Giunta F, Suter PM, Slutsky AS: Mechanical ventilation as a mediator of multisystem organ failure in acute respiratory distress syndrome. JAMA 2000; 284:43-4

15. Stuber F, Wrigge H, Schroeder S, Wetegrove S, Zinserling J, Hoeft A, Putensen C: Kinetic and reversibility of mechanical ventilation-associated pulmonary and systemic inflammatory response in patients with acute lung injury. Intensive Care Med 2002; 28:834-41

16. Abraham E, Carmody A, Shenkar R, Arcaroli J: Neutrophils as early immunologic effectors in hemorrhage- or endotoxemia-induced acute lung injury. Am J Physiol Lung Cell Mol Physiol 2000; 279:L1137- 45

17. Pugin J, Dunn I, Jolliet P, Tassaux D, Magnenat JL, Nicod LP, Chevrolet JC, Pugin J: Activation of human macrophages by mechanical ventilation in vitro. Am J Physiol 1998; 275:L1040-50

18. Mourgeon E, Isowa N, Keshavjee S, Zhang X, Slutsky AS, Liu M: Mechanical stretch stimulates macrophage inflammatory protein-2 secretion from fetal rat lung cells. Am J Physiol 2000; 279:L699-706

19. Ghofrani HA, Rosseau S, Walmrath D, Kaddus W, Kramer A, Grimminger F, Lohmeyer J, Seeger W: Compartmentalized lung cytokine release in response to intravascular and alveolar endotoxin challenge. Am J Physiol 1996; 270:L62-8 20. Tremblay LN, Miatto D, Hamid Q, Govindarajan A, Slutsky AS: Injurious ventilation induces widespread pulmonary epithelial expression of tumor necrosis factor-alpha and interleukin-6 messenger RNA. Crit Care Med 2002; 30:1693700

21. Tutor JD, Mason CM, Dobard E, Beckerman RC, Summer WR, Nelson S: Loss of compartmentalization of alveolar tumor necrosis factor after lung injury. Am J Respir Crit Care Med 1994; 149:1107-11

22. Haitsma JJ, Uhlig S, Lachmann U, Verbrugge SJ, Poelma DL, Lachmann B: Exogenous surfactant reduces ventilator-induced decompartmentalization of tumor necrosis factor alpha in absence of positive end-expiratory pressure. Intensive Care Med 2002; 28:1131-7

23. Haitsma JJ, Uhlig S, Goggel R, Verbrugge SJ, Lachmann U, Lachmann B: Ventilator-induced lung injury leads to loss of alveolar and systemic compartmentalization of tumor necrosis factor-alpha. Intensive Care Med 2000; 26:1515-22

24. Uhlig S: Ventilation-induced lung injury and mechanotransduction: Stretching it too far? Am J Physiol Lung Cell Mol Physiol 2002; 282:L892-6

25. Imanaka H, Shimaoka M, Matsuura N, Nishimura M, Ohta N, Kiyono H: Ventilator-induced lung injury is associated with neutrophil infiltration, macrophage activation, and TGF-beta 1 mRNA upregulation in rat lungs. Anesth Analg 2001; $92: 428-36$

26. von Bethmann AN, Brasch F, Nusing R, Vogt K, Volk HD, Muller KM, Wendel A, Uhlig S: Hyperventilation induces release of cytokines from perfused mouse lung. Am J Respir Crit Care Med 1998; 157:263-272

27. Haslett C: Granulocyte apoptosis and its role in the resolution and control of lung inflammation. Am J Respir Crit Care Med 1999; 160:S5-11

28. Steinberg KP, Milberg JA, Martin TR, Maunder RJ, Cockrill BA, Hudson LD: Evolution of bronchoalveolar cell populations in the adult respiratory distress syndrome. Am J Respir Crit Care Med 1994; 150:113-22 